\title{
Paris plans science in the suburbs
}

\section{Euros flow in to boost French goal of creating critical mass of cross-agency researchers.}

\section{BY DECLAN BUTLER}

$\mathrm{F}$ rance's plans to build a science supercampus - Paris-Saclay - a 30-kilometre drive southwest of the capital are shifting into high gear. President Nicolas Sarkozy officially launched the scheme on 24 September in a speech at the Optical Institute Graduate School at Saclay. His ambition is to make ParisSaclay one of the world's top universities and science parks by 2020 - a Massachusetts Institute of Technology à la française.

Sarkozy announced that several Grandes Ecoles - France's elite higher-education institutes - would be moved from Paris to the Saclay plateau, as would parts of the nearby Orsay campus of France's largest university, University Paris-Sud 11. The 23 partners in Paris-Saclay, which include research agencies, universities and Grandes Ecoles, will each vote later this month on the final governance structure of the project. This body will take the lead in implementing the campus's science strategy, which is being finalized around 12 research themes, including nanotechnology and lowcarbon energy. By concentrating funding, and large numbers of scientists from different research agencies, the government hopes to achieve a critical mass of effort in key sectors. It also hopes that the presence of top academic and corporate labs at Paris-Saclay will help innovation to flourish.

The Saclay plateau already has one of the densest concentrations of research in Europe, including the labs of major French research agencies, the prestigious Ecole Polytechnique and big-science infrastructures such as the SOLEIL synchrotron. It rivals the Massachusetts Institute of Technology (MIT) in Cambridge and Stanford University in California for staff and publications (see 'Saclay sized up'), and boasts the research labs of major companies such as Thalès, Danone and Areva.

But the government believes that Saclay's research, spread across the plateau, is not realizing its full potential. In his speech, Sarkozy described the campus as a "mosaic of institutions, each highly prestigious, but badly coordinated among themselves, and separated by artificial institutional barriers". Such barriers were "totally obsolete in an era of global scientific competition", he said, arguing the case for an overarching-campus strategy.

Although the heads of research centres involved in the Saclay project are enthusiastic, some rank-and-file scientists worry that they have given little input. They generally agree,

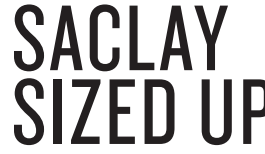

French researchers hope that Paris-Saclay can surpass the output of other leading science campuses.

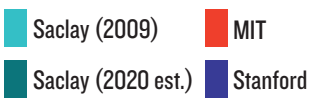

CAMPUS AREA
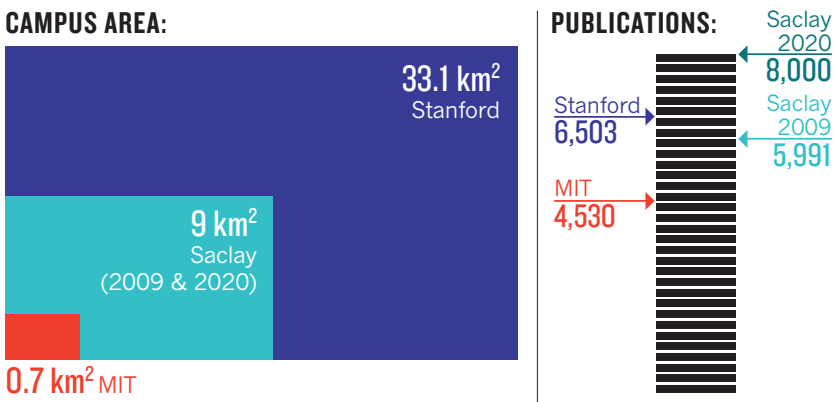

\section{RESEARCHERS:}

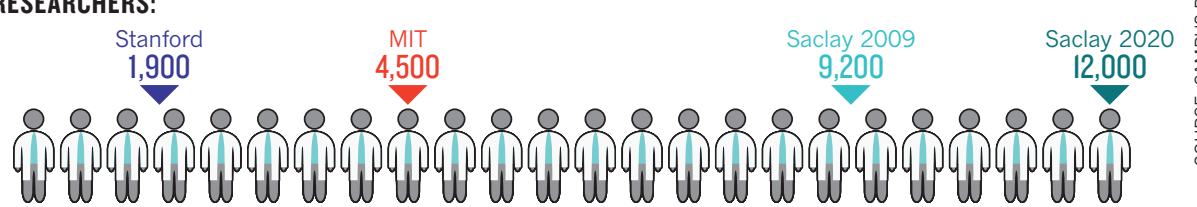

however, that concentrating and restructuring research there is in principle a good idea. And Marion Guillou, chief executive of INRA, the national agricultural research agency, adds that most of the lab moves and campus creation won't take place until 2015-20, leaving ample time for consultation.

The billions of euros the government is pouring into its vision of creating a shared campus, including improved public transport and a suite of new interdisciplinary institutes and labs, is also a strong incentive for researchers to embrace

\section{"In French} culture, reforms are always a little bit scary." change. These centres will bring together groups from different research agencies and universities to work on problems in a diverse range of disciplines, from neuroscience to photovoltaics. By 2020, Paris-Saclay will house some 70,000 people $(25,000$ more than work there currently), including 12,000 researchers, with one-third of the site being occupied by research labs in the private sector.

The cost of the new buildings alone is put at around $€ 4$ billion (US $\$ 5.6$ billion). The campus won an endowment of $€ 850$ million in February 2009 as part of the science ministry's Operation Campus, a $€ 5$-billion plan to refurbish 10 select campuses. Research agencies, universities and other ministries have contributed a further $€ 1$ billion, some of which will come from the sale of valuable real estate in Paris once the labs have moved to Saclay.

Sarkozy announced a further $€ 1$ billion in his speech to help finance the first wave of moves, and the campus has set aside a further $€ 900$ million for student housing. The campus also got $€ 1$ billion from the French economic stimulus package - the Grand Emprunt (big loan) - announced last December (see Nature 462, 838; 2009), and expects further support for infrastructure and grants from the $€ 22$-billion research part of the package.

But researchers involved are concerned by the short deadlines imposed on Grand Emprunt grant proposals by the Paris-based National Research Agency. The first calls for proposals, for some $€ 8.6$ billion in total, were issued during the summer and autumn with submission deadlines of just 3 to 6 months. Many research groups at Saclay are still busy working out how they will collaborate with other partners at the site, and so are "struggling" to put together decent proposals on time, says one senior researcher, requesting anonymity. Without a clear strategy from all the Saclay partners, "we may end up with a collection of rushed projects that do not bring the expected scientific and educational added value", says another senior researcher.

A third researcher, based at Paris-Sud, claims that the project is being "decided topdown with no real thinking of what would be best scientifically". But Hervé Le Riche, the project head, says that scientific directors and lab heads have been deeply involved in developing the campus strategy since last year, and that planning is well advanced.

"In French culture, change is not an essential characteristic," adds Le Riche. "Reforms are always a little bit scary.” — SEENEWS FEATURE P.906

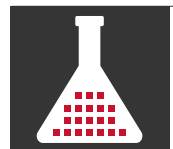
SCIENCE AND THECITY Full content and enhanced graphics at: nature.com/cities 